\title{
O CONTEÚDO LUTAS NO ENSINO MÉDIO: DISCURSOS DOS PROFESSORES DE EDUCAÇÃO FÍSICA DA FRONTEIRA BRASIL- BOLÍVIA
}

\author{
Paulo Cesar Grulett Lopez \\ Universidade Federal De Mato Grosso Do Sul, Corumbá, Mato Grosso Do Sul, Brasil. \\ Carlo Henrique Golin \\ Universidade Federal De Mato Grosso Do Sul, Corumbá, Mato Grosso Do Sul, Brasil. \\ Edineia Aparecida Gomes Ribeiro \\ Universidade Federal De Mato Grosso Do Sul, Corumbá, Mato Grosso Do Sul, Brasil.
}

\begin{abstract}
Resumo
Este trabalho objetivou analisar o discurso dos professores de nível médio sobre a aplicação do conteúdo Lutas nas aulas de Educação Física em Corumbá/MS, cidade fronteiriça BrasilBolívia. Nos baseamos metodologicamente no trabalho de Ferreira (2006), ao adaptarmos o seu modelo de pesquisa. Os resultados apontaram que a maioria (83\%) dos entrevistados têm o conteúdo no seu plano de ensino. Contudo, a maior parte utiliza procedimentos que não oportunizam vivências. Observamos ainda o predomínio da Capoeira a ser trabalhada, ao contrário das Lutas informais. A maioria entende que o conteúdo em debate não gera violência e agressão, mas que isso dependeria da atitude do professor. Nossos resultados se aproximam do estudo tomado como referência e apontam outras preocupações sobre o tema. Palavras-chave: Lutas. Educação Física. Ensino Médio.
\end{abstract}

\section{THE CONTENT FIGHTS IN MIDDLE SCHOOL: SPEECHES OF PHYSICAL EDUCATION TEACHERS FROM THE BRAZIL-BOLIVIA BORDER}

\begin{abstract}
The objective of this study was to analyze the discourse of middle level teachers on the application of content Fights in the classes of Physical Education in Corumbá / MS, border city Brazil-Bolivia. We base methodologically on the work of Ferreira (2006) when adapting his research model. The results showed that the majority $(83 \%)$ of respondents had the content in their teaching plan. However, the vast majority use procedures that do not provide experience. We also observed the predominance of Capoeira to be worked on, unlike the informal struggles. Most understand that the content under debate does not generate violence and aggression, but that this would depend on the teacher's attitude. Our results approximate the study taken as reference and point out other concerns about the theme.
\end{abstract}

Key-words: Fights. Physical Education. High School. 


\title{
EL CONTENIDO LUCHAS EN LA ENSEÑANZA MEDIO: DISCURSOS DE LOS MAESTROS DE EDUCACIÓN FÍSICA DE LA FRONTERA BRASIL-BOLIVIA
}

\begin{abstract}
Resumen
El trabajo objetivó analizar el discurso de los maestros de nivel medio sobre la aplicación del contenido Luchas en las clases de Educación Física en Corumbá/MS, ciudad fronteriza BrasilBolivia. Basamos, metodológicamente, en el trabajo de Ferreira (2006) al adaptar su modelo de investigación. Los resultados apuntaron que la mayoría (83\%) de los entrevistados tienen el contenido en su plan de enseñanza. Sin embargo, la gran parte utiliza de procedimientos que no oportunizan vivencias. Observamos también el predominio de la Capoeira a ser trabajada, al contrario con las Luchas informales. La mayoría entiende que el contenido en debate no genera violencia y agresión, pero que eso dependería de la actitud del profesor. Nuestros resultados se aproximan al estudio tomado como referencia y apuntan otras preocupaciones sobre el tema.
\end{abstract}

Palabras clave: Luchas. Educación Física. Enseñanza Media.

\section{Introdução}

É notória a importância das diferentes formas de atividades físicas na construção sociocultural dos seres humanos ao longo do tempo, elas marcam presença desde as sociedades pré-históricas até os dias contemporâneos. Contudo, na trajetória da atividade física de combate (Lutas) existe uma relação direta entre a sobrevivência dos seres humanos, por exemplo, na apropriação de territórios, o que demonstra nessa manifestação corporal distintas questões sociais, culturais, políticas, esportivas entre outras (SILVA; MITHIDIERI; NOVIKOFF, 2014).

O termo Luta pode ter diferentes significados, bem como nos remeter a um embate violento entre pessoas, embates empresariais, disputas de classe sociais etc. Em determinados contextos, a expressão também se relaciona com uma forma de resistir à determinada opressão. Por exemplo, no Brasil temos uma manifestação muito popular denominada de Capoeira, que historicamente alia-se ao movimento de preservação cultural e, ao mesmo tempo, foi um meio de preservar a vida de um povo que estava sendo escravizado. Lembrando que, a despeito da abolição da escravidão, a Capoeira foi perseguida por décadas (FONTOURA; GUIMARÃES, 2002).

Trazendo o debate para o ambiente educacional, as Lutas, quando inseridas no currículo escolar, podem auxiliar os educandos a expressarem e extravasarem sentimentos que tangenciam a agressividade, porém de forma controlada, equilibrada e disciplinada, dentro de um contexto pedagógico que pode potencializar movimentos corporais e possibilitar o trabalho com temas como: ética e valores humanos (FERREIRA, 2009).

O conteúdo Lutas na Educação Física escolar, dentro da lógica educacional, necessita superar um certo estigma ligado à geração da agressividade e violência. Hoje, esse conteúdo é um esporte de autodefesa que não gera violência, pelo contrário, fortalece o entendimento dos sentimentos e ajuda na compreensão de fenômenos sociais e culturais (GOMES, 2014). Assim, de acordo com Ferreira (2006, p. 37), o conteúdo Lutas no contexto educacional não seria somente "[...] as modalidades tidas como tradicionais (Judô, Caratê, Kung Fu), mas, também, a prática da luta informal”, incluindo as inúmeras outras brincadeiras populares do contexto brasileiro (cabo de guerra, braço de ferro...).

Além disso, algumas pesquisas apontam que o modo como o professor analisa, organiza e aplica o conteúdo Lutas nas aulas de Educação Física escolar pode estar diretamente relacionado ao processo de formação acadêmica deste profissional, o que indica 
uma necessidade de adequação das propostas no Ensino Superior para valorizar essas manifestações corporais (RUFINO; DARIDO, 2015).

Esclarecemos que os movimentos básicos encontrados nas Lutas, como chutes, socos, rasteiras, projeção entre outras atividades realizadas por meio da ludicidade, podem ser elementos motores significativos para introduzir o conteúdo na escola. Portanto, o conteúdo Lutas pode ser mais um instrumento de auxílio pedagógico para o professor de Educação Física, sobretudo ao considerar que o "ato de Lutar", no sentido educativo, precisa interrelacionar o contexto histórico, social e cultural.

Percebemos, por meio de nossas experiências e algumas pesquisas (OLIVEIRA, 2018; RUFINO; DARIDO, 2015; OLIVEIRA; GOMES; SUZUKI, 2015), que existem muitos desafios para o desenvolvimento do conteúdo Lutas nas aulas de Educação Física escolar, alguns deles seriam: espaço inadequado; escassez de estudos específicos em relação ao desenvolvimento do conteúdo Lutas no Ensino Médio; medo por parte do docente devido à falta de conhecimento entre outros. Por isso problematizamos: o conteúdo Lutas está presente nos planos de ensino dos professores de Educação Física do Ensino Médio? Os professores utilizam esse conteúdo? De que forma esse conteúdo é trabalhado nas aulas? É possível trabalhar Lutas com os jovens nessa modalidade de ensino?

Assim, com base nesses parâmetros e questionamentos, este trabalho tem como finalidade esclarecer e desmitificar, especialmente para o professor de Educação Física, o conteúdo Lutas, explicitando-o como uma possibilidade salutar a ser desenvolvida no Ensino Médio. Portanto, a pesquisa teve por objetivo geral identificar e analisar quais são as principais potencialidades e/ou dificuldades dos professores de nível médio quanto à aplicação do conteúdo Lutas nas aulas de Educação Física nas escolas públicas e privadas de Corumbá/MS, cidade situada na fronteira Brasil-Bolívia.

\section{Lutas e sua inserção na Educação Física escolar}

Segundo Lançanova (2006), as Lutas estão inscritas nas manifestações corporais de um povo por meio da cultura. Sua origem está ligada ao surgimento da espécie humana, já que os nossos ancestrais precisavam se movimentar de forma a se defender e/ou atacar um oponente. Na história da humanidade a Luta passou de uma forma de preservação e sobrevivência para outras formas culturalmente elaboradas, podendo ser expressadas em diferentes esportes, rituais religiosos, batalhas/guerras entre outros (BREDA et al., 2010).

Há registros de artes marciais de mais de cinco mil anos, como o Kung $F u$ na China. Lançanova (2006) afirma que o termo Luta define algo mais amplo, aplicado em ações que envolvem oponentes variados, já a arte marcial seria uma manifestação voltada para o combate específico, incluindo muitas vezes filosofias e tradições. Podemos afirmar que as artes marciais - incluindo o Boxe - seriam a expressão da eterna busca por autoconhecimento. O Jeet Kune Do é um exemplo disso, pois possui características particulares como preliminares ao treino, aquecimento, posição de guarda, quadros das armas, oito posições básicas de defesa e alguns alvos. A base das artes marciais é o entendimento das técnicas e, segundo Lee (2003), ela se assemelha com o budismo, sugerindo uma interação de equilíbrio entre "corpo e espírito".

Por outro lado, no contexto brasileiro, a capoeira foi uma invenção do negro na África, onde existia como forma de dança ritualística. Enquanto escravos, em solo brasileiro, os negros de origem africana deram à capoeira um sentido de resistência diante da opressão de capatazes e senhores de engenho (FONTOURA; GUIMARÃES, 2002). Mais recentemente apresentou grande popularidade com a atuação do Mestre Bimba, que idealizou e criou a Capoeira Regional, realizando uma ruptura com a ideia de marginalidade. Atualmente, a capoeira é reconhecida como "Esporte Nacional". A importância do Mestre Bimba foi 
reconhecida em 1957 por meio do título oficial de Instrutor de Educação Física outorgado pelo Ministro da Educação (MORENO; GARCIA, 2011).

Dessa maneira, as Lutas passaram a ser consideradas pelos pesquisadores como conteúdos históricos da área da Educação Física escolar, até mesmo já sistematizados nos Parâmetros Curriculares Nacionais (PCN's). No estado de Mato Grosso do Sul, o conteúdo é também citado no referencial curricular. Isto é, as Lutas são conteúdos históricos que devem ser abordados e contemplados nas aulas de Educação Física, mas existem alguns argumentos desfavoráveis à prática de ensino, como: a falta de vivência de uma parte dos professores com o conteúdo de Lutas e a preocupação com a violência que se imagina que as Lutas possam gerar. Trata-se de pré-conceitos ligados às expressões: "Luta machuca", "Luta é briga", "Luta é para encrenqueiro".

Uma oposição a esse tipo de pensamento pode ser observada nos próprios PCN's (BRASIL, 1998, p. 37), em especial quando caracterizam que as Lutas são:

[...] disputas em que o(s) oponente(s) deve(m) ser subjugado(s), mediante técnicas e estratégias de desequilíbrio, contusão, imobilização ou exclusão de um determinado espaço na combinação de ações de ataque e defesa. Caracterizam-se por uma regulamentação específica, a fim de punir atitudes de violência e de deslealdade. Podem ser citados como exemplo de lutas desde as brincadeiras de cabo-de-guerra e braço-de-ferro até as práticas mais complexas da capoeira, do judô e do caratê.

Outras variações conceituais sobre Lutas são apresentadas por Leite et al. (2012, p. 04), os autores relatam que

As Lutas podem ser compreendidas como uma manifestação cultural, dependendo da maneira como é aplicada pode ser considerada como atividade rítmica, jogo de oposição, esporte de combate ou arte marcial. Há uma variedade de possibilidades pedagógicas, o importante é a forma que será aplicada, os valores que serão ensinados através dessa cultura corporal.

Já Chaves, Silva e Medeiros (2014) citam o caráter heterogênico do conteúdo Lutas, de forma que os profissionais de Educação Física podem realizar diferentes abordagens desse tema nas aulas, sem desconsiderar as particularidades de cada educando.

Num outro prisma, considerando a relação entre Lutas e violência, Chianca et al. (2016, p. 74) afirmam que: "[...] pensar a violência como consequência do trabalho com as lutas é um equívoco, visto que, o trato com as lutas, especialmente as artes marciais, normalmente é acompanhado de reflexões, disciplina e controle dos próprios ímpetos do praticante". Oliveira (2018) reforça essa ideia ao ponderar que, apesar de o tema Lutas ser frequentemente ligado à agressividade, paradoxalmente ele também é associado ao desenvolvimento da disciplina, ética e respeito entre os praticantes. Por isso, compreendemos que a origem da violência é muito mais complexa e que ela pode estar ligada a inúmeras questões sociais (MELLO, 2016).

Rufino e Darido (2015), por sua vez, afirmam que os elementos de dificuldade para inserção do tema Lutas nas aulas de Educação Física têm sua origem na falta de domínio teórico e em uma abordagem superficial dispensada ao tema na escola. Nesse sentido, Santomauro (2011, s/p) considera que para desenvolver o tema, o docente não necessariamente deve

[...] ser um atleta que saiba lutar [...]. O essencial é estudar o assunto - tal como se faz com outros, como futebol e alongamento [...]. Outro ponto importante [...] é que o objetivo não pode ser transformar os alunos em lutadores profissionais [...]. A ideia é fazer com que eles conheçam as características comuns às lutas, as técnicas, o histórico, as vestimentas e os países em que as lutas são praticadas. 
É importante destacar que as Lutas também se relacionam com a cultura de um povo, portanto cada contexto possui e expressa características tradicionais ligadas à sua manifestação, conforme destaca Oliveira, Gomes e Suzuki (2015, p. 09):

[...] poderíamos dizer que existe, para cada país, uma forma de luta típica. Por exemplo: Damnyè ou Ladja da Martinica, no Caribe. O Many de Cuba. Cheibi gad ga de Manipur na Índia, Chausson ou Savate francês, Escrima ou Arnis das Filipinas, Krabi-krabong e Muaythai da Tailândia, Guresh da Turquia, Glima da Islândia, Pentjak silat da Indonésia, Gouren Bretão e o Uka uka de índios no alto $\mathrm{Xingu}$, entre outros. Também podemos enquadrar como lutas folclóricas e culturais as brincadeiras infantis, realizadas em forma de confronto. Enquadram-se aqui os desafios de cabo de guerra, desafios de desequilíbrio, as brigas de galo, e outros, típicos de conteúdos das aulas de Educação Física infantil.

Portanto, as diferentes demandas sobre o conteúdo Lutas acabam gerando incertezas pedagógicas e potencialidades devido a sua amplitude histórica e sociocultural, oportunizando um campo rico para pesquisas sobre esse fenômeno, sobretudo enquanto conteúdo que pode ser trabalhado pela Educação Física no contexto escolar.

\section{Metodologia}

Esta pesquisa é um recorte dos dados secundários de um projeto maior que estuda adolescentes da região fronteiriça Brasil-Bolívia em Corumbá/MS e que foi aprovado pelo Comitê de Ética em Pesquisa com Seres Humanos da Fundação Universidade Federal de Mato Grosso do Sul (UFMS), sob protocolo de número 1.802.998. O projeto teve como finalidade avaliar os adolescentes do Ensino Médio, bem como os professores de Educação Física e os conteúdos trabalhados nas aulas. Dessa forma, para tratar do tema do presente estudo, tomamos como modelo o trabalho de Ferreira (2006), o qual foi escolhido por conveniência e também por abarcar o Ensino Médio. Esse tipo de escolha permite fazer comparações interessantes, já que o contexto social é outro, surgiram novos desafios e/ou paradigmas da área, em especial porque já transcorreram 12 anos até o momento da pesquisa.

Dessa forma, adotamos uma abordagem qualitativa, de caráter analítico descritivo, e isso nos permitiu, enquanto pesquisadores, a explanação a respeito do fenômeno investigado (GERHARDT; SILVEIRA, 2009). Para realizar esse intento, adaptamos o questionário da pesquisa de campo desenvolvida por Ferreira (2006) para ser aplicado em nossa realidade local, focando no nível médio de ensino e com aumento do viés qualitativo nas indagações, principalmente ao solicitar dos entrevistados as justificativas sobre as suas respostas. Assim, nosso trabalho teve um questionário elaborado com seis questões (abertas/fechadas).

Ressaltamos que Ferreira (2006) pesquisou 50 professores de Educação Física, de ambos os sexos, que atuam na rede pública e particular das escolas de Fortaleza/CE (Brasil). Seguimos os mesmos trâmites metodológicos da referida pesquisa, porém adaptamos o questionário que era, exclusivamente, com perguntas fechadas. Destacamos que nossa pesquisa foi somente com professores que atuam no Ensino Médio, oriundos da cidade de Corumbá (pública e privada), cidade fronteiriça (Brasil-Bolívia) localizada no Oeste do Estado de Mato Grosso do Sul (MS).

Desse modo, com autorização da Coordenadoria Regional de Ensino (CRE-3 Corumbá/MS) e de forma voluntária, realizamos visitas nas escolas para obter mais informações sobre o número de alunos e professores. No total são 11 escolas públicas e quatro 
privadas. Desse total conseguimos os dados de nove escolas públicas ${ }^{1}$ ( $82 \%$ do total) e duas escolas privadas $^{2}(50 \%$ do total).

Selecionamos, a partir dos dados coletados, nossa amostra para a pesquisa considerando alguns critérios de exclusão e inclusão. Do número total de escolas a que tivemos acesso aos dados dos alunos matriculados, elegemos um número mínimo de 50\%, ficando 6 escolas públicas (55\% do total) e 2 escolas privadas (50\% do total) que ofereciam o Ensino Médio, em especial aquelas que compreendiam as unidades educativas com maior número de alunos matriculados; optamos por selecionar as turmas do ensino regular diurno, selecionamos também todos os professores de Educação Física efetivos das escolas envolvidas na amostra.

Coletamos os dados entre março e maio de 2018, e verificamos um total de 13 docentes, contudo foram entrevistados 12 professores, sendo dez da rede pública e dois professores da rede privada ${ }^{3}$. Todos os professores selecionados tiveram uma explicação geral sobre a pesquisa, além da leitura e assinatura do Termo de Consentimento Livre e Esclarecido. Os dados pessoais dos entrevistados foram suprimidos, dessa forma utilizamos números e abreviações, conforme estes exemplos: Professor(a) 1PU (PU= rede pública); Professor(a) 2PR ( $\mathrm{PR}=$ rede privada).

\section{Resultados e discussões}

$\mathrm{Na}$ sequência apresentamos, de acordo com nossos objetivos e o problema, os questionamentos, as respostas dos entrevistados e sua articulação/discussão com o tema em debate.

A primeira pergunta da entrevista abordou a previsão do conteúdo Lutas no plano de ensino dos professores entrevistados; observamos que dos 12 professores questionados, dez $(83,33 \%)$ afirmaram que estava prevista nos planos a utilização do conteúdo em suas aulas e $02(16,66 \%)$ relataram que não previram o conteúdo Lutas em 2018. Podemos notar que existe um número expressivo de professores que se propõem a utilizar as Lutas. Esse fato pode ser explicado pela constante presença e debate cada vez maior acerca do tema Lutas, até mesmo porque é um conteúdo presente nos Parâmetros Curriculares Nacionais (PCN's) documento amplamente conhecido e disseminado nas escolas brasileiras. A previsão de trabalho com o conteúdo pode se dar por sua presença histórica na escola e/ou pelo processo de formação dos profissionais, que possivelmente tomaram conhecimento do tema nas últimas décadas - o que pode ser melhor explicado em pesquisas futuras.

Apesar de somente dois professores relatarem que não incluem o conteúdo Lutas em seus planos de ensino, a aplicabilidade desse conteúdo no Ensino Médio ainda merece atenção no âmbito educativo (escolar). Esse fato, no campo planejamento, pode ser contraditório e estar relacionado a não presença/negligência do conteúdo Lutas na prática da disciplina Educação Física escolar, em especial na região fronteiriça (Brasil-Bolívia) do estudo. Verificamos, ainda, que os dados encontrados se contrapõem aos obtidos por Ferreira (2006), em que $68 \%$ dos professores disseram nunca ter inserido tais temas em suas aulas. A respeito dessa postura, o autor aponta que os profissionais estão

[...] preferindo manter a velha pedagogia da bola em suas aulas, pouco inovando ou não experimentando novas formas de ministrar suas aulas. É mais cômodo ao professor ministrar aulas de futebol, de voleibol ou de qualquer outra atividade com

\footnotetext{
${ }^{1}$ Esse número é reflexo da exclusão de uma escola que se localiza na região pantaneira (indígena) e de outra por não ter autorização da Direção escolar.

${ }^{2}$ Esse número reduzido foi devido à dificuldade de comunicação e autorização por parte das unidades escolares.

${ }^{3}$ Um professor, de uma escola privada, não autorizou a realização da entrevista.
} 
bola, do que preparar aulas envolvendo um tema tão complexo como as lutas (FERREIRA, 2006, p. 42).

Já quando questionamos aqueles que iriam utilizar o tema Lutas nas aulas de Educação Física, demos cinco opções de respostas: (A) através de práticas recreativas/lúdicas; B) através da ajuda de um especialista; C) através de vídeos; D) através de aula de campo; E) outras alternativas (neste caso deveriam especificar). Assim, identificamos que os entrevistados indicaram quatro $(40 \%)$ vezes a alternativa A; quatro $(40 \%)$ vezes a alternativa $\mathrm{B}$; seis $(60 \%)$ vezes a alternativa C; uma (10\%) vez a alternativa D e também uma (10\%) vez a alternativa E. Com isso, podemos notar que a forma de ministrar as aulas de Lutas por esses docentes nem sempre é "prática". Por exemplo, dentre os que afirmaram utilizar o tema, notamos que coexiste a utilização de ilustrações (mídias-imagens) e "teóricas", conforme podemos observar a seguir:

"Através de trabalhos (pesquisas), pois não tenho instrução e a escola não tem um colaborador" - 2PU.

"Através de slides sobre a origem das lutas, aonde os alunos podem conhecer, identificar suas características rituais de disciplinas, controle e demais aspectos" - 3PU.

“As aulas são expositivas através de pesquisa”-6PU.

Essas conduções didáticas também foram encontradas nas pesquisas de Ferreira (2006), em que 50\% dos professores utilizam exclusivamente vídeo para tratar do tema. O mesmo autor aponta que, embora poucos profissionais utilizem Lutas de forma lúdica, essa seja a melhor maneira de introduzir o tema, ressaltando os benefícios cognitivos, físicos e emocionais de tal prática.

A visão descrita anteriormente possui semelhança com as afirmações dos professores:

"Ela é uma ferramenta para formação do cidadão, com o objetivo de disciplina e autocontrole, diante de situações como violência e descontrole”-3PU.

"Ela é uma prática que disciplina, ajuda no desenvolvimento físico e mental. Busca a elevação do caráter, o respeito mútuo" - 8PU.

Dos dois docentes $(16,66 \%)$ que assinalaram "não" utilizar o conteúdo Lutas em suas aulas de Educação Física, um afirma não ter instrução para o desenvolvimento do tema e o outro não citou qual seria o motivo para não desenvolver o conteúdo em questão.

$\mathrm{Na}$ terceira questão buscamos compreender quais seriam as Lutas aplicadas/utilizadas pelos professores, nesse caso considerando os pesquisados que responderam sim na pergunta anterior. Dessa forma, considerando os 10 professores que informaram utilizar as Lutas, as alternativas de conteúdo escolhidas foram: uma (10\%) vez o Boxe; cinco (50\%) vezes a Capoeira; uma (10\%) vez o Caratê; duas (20\%) o Tae-Kwon-Do e outras duas (20\%) vezes o Jiu-Jítsu.

Observamos ainda a predominância do relato da Capoeira como modalidade a ser empregada, o que pode ser explicado por sua presença histórica no Brasil e por ser disseminada como alternativa pedagógica pelos PCN's. Outra hipótese é a presença expressiva do Candomblé e da Umbanda na cidade de Corumbá (região) que, por sua vez, são religiões intimamente ligadas às origens da Capoeira.

No questionário, por exemplo, o educador 11PR assim pontuou: "As lutas são dotadas de regras e todo um conceito histórico" (grifo nosso). Já na pesquisa de Ferreira (2006), a 
Capoeira foi relatada por apenas $26 \%$ dos professores; esse mesmo autor aponta que a Capoeira deve ser trabalhada de forma contextualizada, relacionando-a ao processo histórico de escravidão que foi expressivamente vivenciado no Brasil.

Em relação aos discursos dos entrevistados, não notamos justificativas a respeito da presença de atividades e/ou brincadeiras lúdicas não tradicionais (Lutas simples) que se associassem ao conteúdo Lutas sistematizadas. Essa realidade é denunciada por Ferreira (2006, p. 37) quando descreve que: "Entende-se como lutas, não somente as modalidades tidas como tradicionais (Judô, Caratê, Kung Fu), mas, também, a prática da luta informal".

Já na quarta questão buscamos compreender qual o conceito de Lutas os professores possuem, essa pergunta foi feita de forma idêntica à de Ferreira (2006, p. 42), vejamos: "Você considera que as Lutas são apenas as formas preexistentes, como Caratê, Boxe, Capoeira ou acha que cabo de guerra e braço de ferro também são formas de Luta?". Como alternativas seguimos também o mesmo protocolo do autor: “A) Somente as técnicas preexistentes podem ser consideradas Lutas. B) Qualquer atividade em que dois oponentes se enfrentam, tentando superar o outro é um tipo de Luta".

Dos 11 professores que responderam a quarta questão, quatro deles $(36,66 \%)$ consideraram que Lutas seriam somente as técnicas preexistentes de combate, enquanto sete $(63,63 \%)$ afirmaram que qualquer atividade em que dois oponentes se enfrentam pode ser um tipo de Luta.

No resultado da quarta questão predominou a concepção de Lutas como um jogo de oposição e disputa. Algo também contraditório se considerarmos os resultados da pergunta anterior a ela, particularmente quando nos discursos dos entrevistados não aparecem a presença de atividades e/ou brincadeiras lúdicas como alternativas. Nos estudos de Ferreira (2006) o resultado é oposto, 64\% dos professores não entendem a Luta em sua forma mais diversificada, assim a maioria dos seus pesquisados considerou apenas Caratê, Judô, Capoeira e outras modalidades como Lutas.

$\mathrm{Na}$ quinta questão, os professores foram indagados sobre o seu entendimento e/ou percepção quanto à relação da prática de Lutas e a geração de violência. Nessa pergunta demos aos entrevistados três alternativas, igualmente como Ferreira (2006) fez, são elas: A) Sim, B) Não, C) Depende do professor. Contudo, acrescentamos que o entrevistado deveria justificar/explicar a sua resposta. Assim, os resultados demonstram que somente um professor respondeu "Sim", nove deles assinalaram "Não" e dois docentes afirmaram que "Depende do professor". Os nossos resultados foram similares aos apresentados por Ferreira (2006).

Também destacamos que o educador 2PU considerou que as Lutas podem gerar violência e, para tanto, afirmou que os educandos podem distorcer a finalidade do conteúdo Lutas. Vejamos a seguir sua justificativa:

"Fora das aulas os alunos apresentam um comportamento diferente, podendo utilizar de forma errada tudo aquilo que aprendeu" - 2PU.

Dos nove professores que consideram "Não" haver relação entre a prática de Lutas e a geração de violência, um sujeito acabou não justificando os motivos e os demais ponderaram que:

"As lutas têm suas filosofias voltadas para a defesa e relaxamento interior, que deverão ser abordadas pelo professor instrutor" - 1PU.

"Ela é uma ferramenta para formação do cidadão com objetivo de disciplina e autocontrole, diante de situações como violência e descontrole" - 3PU. 
“Brigas X Lutas - diferentes"- 5PU.

"Ela é uma prática que disciplina, ajuda no desenvolvimento físico e mental. Busca a elevação do caráter, o respeito mútuo" - 8PU.

"Não gera violência, pois o aluno que pratica lutas aprende fundamentos metodológicos de como respeitar seu adversário e praticar lutas somente dentro da academia e em competições" - 9PU.

"O professor deve sempre orientar os alunos que o praticante de lutas deve se defender, não provocar brigas por lutar uma arte marcial” - 10PU.

“As lutas são dotadas de regras e todo um conceito histórico" - 11PR. 12PR.

"Desde que seja ministrada por professores conhecedores dos princípios desta luta" -

Já os dois entrevistados que disseram que as Lutas e a sua possível geração de violência dependeriam do professor pontuaram que:

"O professor enquanto educador tem que fazer com que o aluno reconheça os princípios éticos que as lutas têm como características”- 4 PU.

"Depende da forma como o conteúdo é apresentado, se é trabalhado a filosofia através dos movimentos ou apenas apresentado os golpes" - 7PU.

Podemos notar que, de acordo com a maioria das respostas e justificativas, não existe associação entre as Lutas e a geração da violência, pelo contrário, as descrições valorizam os princípios éticos e o distanciamento da ideia de Lutas como atos violentos entre as pessoas (brigas). Os professores fizeram também alguns alertas sobre a forma de condução do conteúdo.

Na sexta questão buscamos compreender se as práticas de Lutas tornariam os alunos mais agressivos. Dessa forma, demos aos entrevistados 3 alternativas, assim como Ferreira (2006) fez: A) Sim, B) Não, C) Talvez. Contudo, acrescentamos que o entrevistado deveria justificar/explicar a sua resposta. Os resultados mostraram que 11 professores responderam "Não" e somente um deles assinalou a alternativa "Talvez", justificando que isso dependerá das características particulares de cada pessoa, assim ele descreve:

"Cada pessoa é um ser humano diferente, que age de acordo com seu temperamento, princípios e modo de pensar" - 2PU.

Isso pode indicar que não seria o conteúdo em si que geraria a violência, mas a forma como este é conduzido conforme a personalidade individual, por exemplo.

Dos professores que responderam "Não", apenas um (10PU) não justificou, os demais indicaram diversos fatores (condução pedagógica, metodologia, solidariedade, filosofia...), com preponderância do elemento "disciplinar" envolvido com o conteúdo. Os resultados demonstram, dessa forma, que as práticas de Lutas na verdade podem minimizar e/ou evitar episódios agressivos, especialmente ao valorizar a disciplina, a ética, o respeito e o autocontrole, influenciando o desenvolvimento do caráter do sujeito praticante. 


\section{Considerações finais}

As Lutas fazem parte do desenvolvimento ontogenético da humanidade, assumindo ao longo do tempo características diversas e objetivos distintos entre si. Essa diversidade exige de nós, professores, o discernimento das manifestações vinculadas às diferentes modalidades (esportivas) de Lutas.

Consideramos que o conteúdo Lutas pode ser trabalhado também em outras disciplinas, para compreensão, por exemplo, do seu aspecto histórico. Essa interdisciplinaridade que envolve o conteúdo pode ajudar no debate sobre a questão dos movimentos de resistência de um povo, como o da Capoeira no Brasil. Assim, as Lutas estão para além dos movimentos motrizes, pois auxiliam também na formação do caráter do sujeito.

Além disso, há a formação acadêmica que envolve as especificidades do conteúdo Lutas, ação primordial para que estas sejam devidamente aplicadas em sala de aula, durante o exercício profissional do educador.

Portanto, uma formação acadêmica que incorpore o conteúdo Lutas proporciona ao professor o devido embasamento teórico e prático. Em nossa pesquisa, dois educadores afirmaram que a falha na formação é um dos motivos para não aplicarem Lutas em suas aulas.

Os nossos resultados corroboram o que havíamos conjecturado, sobretudo quanto à dificuldade de aplicar Lutas devido a questões como a falta de estrutura física da escola e de conhecimento específico insuficiente do professor. Trata-se de gargalos que afetam a metodologia utilizada pelos professores para a aplicação desse conteúdo. A maioria (83\%) dos entrevistados diz ter o conteúdo Lutas no seu plano de ensino. Notamos, assim, apenas o elemento teórico sendo trabalhado, o que relega às Lutas um papel secundário em relação à "práxis educacional".

Uma das hipóteses elencadas no início do nosso trabalho foi a de que as Lutas ainda eram consideradas, equivocadamente, como uma forma de estimular a agressividade nos alunos. Entretanto, a pesquisa trouxe dados divergentes e a maioria dos educadores assegurou que o conteúdo e a aplicação das Lutas não gera violência, nem mesmo aumenta a agressividade. $\mathrm{O}$ mesmo resultado foi obtido quando perguntamos se o aluno praticante de Lutas se tornaria agressivo.

De acordo com os resultados do presente estudo, podemos destacar que os temas propostos pelos PCN's (Educação Física) estão sendo aplicados pelos profissionais da área, mesmo que a metodologia não enfoque o elemento "prático". Isso também indica contradições quando comparado ao conhecimento dos próprios entrevistados sobre o conceito do tema. Assim, constatamos nas entrevistas que o tema é pouco trabalhado nas aulas de Educação Física do Ensino Médio da região. Consideramos inclusive que, para uma aula diversificada, devemos aplicar o conteúdo Lutas de forma crítica, desafiadora, inovadora e criativa.

Observamos também que os professores necessitam de aprimoramento - específico sobre Lutas - para que incluam a prática das Lutas de forma eficaz e com confiança, ainda que aparentemente a maioria dos entrevistados tenha apresentado uma visão ampliada sobre Lutas. Por fim, nossos resultados sugerem outros estudos sobre o tema, especialmente para diminuir as limitações e aumentar as potencialidades desse conteúdo para as aulas de Educação Física escolar. Sugerimos também que o tema seja abordado por outras disciplinas escolares, contribuindo assim para o enriquecimento acerca do conceito de Lutas. 


\section{Referências}

BRASIL. Parâmetros Curriculares Nacionais: Educação Física. Brasília: Secretaria de Educação Fundamental, MEC/SEF, 1998.

BREDA, M. et al. Pedagogia do esporte aplicada às lutas. São Paulo, SP: Phorte, 2010.

CHAVES, P. N.; SILVA, I. L. da; MEDEIROS, R. M. N. de. Lutas na educação física escolar: uma experiência no ensino médio. Cadernos de Formação RBCE, p. 80-91, set. 2014.

CHIANCA, A. G. L. et al. Lutas na Educação Física Escolar. REDFOCO. Vol. 3, n.1, 2016. Disponível em: http://periodicos.uern.br/index.php/redfoco/article/view/1810/983. Acesso em: 20 mai. 2018.

FERREIRA, H. S. A utilização das lutas como conteúdo das aulas de Educação Física. Revista Digital - Buenos Aires -, ano 13, n 130, mar. 2009. Disponível em: http://www.efdeportes.com/efd130/lutas-como-conteudo-das-aulas-de-educacao-fisica. Acesso em: 20 mai. 2018.

FERREIRA, H. S. As Lutas na Educação Física Escolar. Revista de Educação Física, Fortaleza, n.135, p. 36-44, nov. 2006.

FONTOURA, A. R. R.; GUIMARÃES, A. C. de A. História da capoeira. R. da Educação Física/UEM, Maringá, v. 13, n. 2, p. 141-150, 2. sem. 2002.

GERHARDT, T. E.; SILVEIRA, D. T. (Orgs.). Métodos de pesquisa. $1^{\circ}$ edição. Porto Alegre: Editora da UFRGS, 2009.

GOMES, V. T.; PINTO, S. G. O ensino de lutas como conteúdo da educação física escolar. Revista@rgumentam, Faculdade Sudamérica, v. 6, p. 181-196, 2014.

LANÇANOVA, J. E. S. Lutas na Educação Física Escolar: alternativas pedagógicas. 2006. 70 f. Monografia (Licenciatura em Educação Física) - Universidade da Região da Campanha, Alegrete, 2006.

LEE, B. O Tao do Jeet Kume Do. Tradução: Tatiana Ori-Kovacs. São Paulo: Conrad Editora do Brasil, 2003.

LEITE, F. F. et al. A utilização das lutas enquanto conteúdo da educação física escolar nas escolas estaduais de Araguaína-TO. Revista Científica do ITPAC, Araguaína, v. 5, n. 3, pub. 3, jul. 2012.

MELLO, T. L. A origem da violência nas aulas de educação física: a prática pedagógica do professor. Dissertação (Mestrado) - Universidade Federal de São Carlos, UFSCar, 2016.

MORENO, S. T. S.; GARCIA, D. A capoeira como elemento da cultura social e sua importância como conteúdo da educação física escolar. In: III Encontro Científico e Simpósio de Educação Unisalesiano, Lins, 17 - 21 de outubro de 2011. Anais eletrônicos... Lins: UniSALESIANO, 2011. Disponível em: 
http://www.unisalesiano.edu.br/simposio2011/publicado/artigo0115.pdf. Acesso em: 20 mai. 2018.

OLIVEIRA, A. L. de; GOMES, F. R. F.; SUZUKI, F. S. Conceito dos tipos de Lutas a partir de uma visão de Cultura Corporal. ACADEMOS - Revista Eletrônica da FIA, 24 jan. 2015. Disponível em:

https://www.researchgate.net/profile/Frank_Shiguemitsu_Suzuki/publication/266036943_CO NCEITO_DOS_TIPOS_DE_LUTAS_A_PARTIR_DE_UMA_VISAO_DE_CULTURA_CO RPORAL/links/54c3fb690cf219bbe4ecd896/CONCEITO-DOS-TIPOS-DE-LUTAS-APARTIR-DE-UMA-VISAO-DE-CULTURA CORPORAL.pdf?origin=publication_detail. Acesso em: 20 mai. 2018.

OLIVEIRA, J. F. Reflexões sobre o conteúdo lutas na educação física escolar. In: GOLIN, C. H; SILVA, J. V. P. da; PACHECO NETO, M. (Org.). Educação física e suas pluralidades, 1 ed., Várzea Paulista/SP, Fontoura Editora, 2018.

RUFINO L. G. B., DARIDO, S. C. O ensino das lutas nas aulas de educação física: análise da prática pedagógica à luz de especialistas. Rev. Educ. Fís/UEM, v. 26, n. 4, p. 505-518, 4. trim. 2015.

SANTOMAURO, B. O lugar da luta nas aulas de Educação Física. Revista Nova Escola, 01 fev. 2011. Disponível em: https://novaescola.org.br/conteudo/1229/o-lugar-da-luta-nas-aulasde-educacao-fisica. Acesso em: 20 de maio de 2018.

SILVA, B. R. da; MITHIDIERI, O. B.; NOVIKOFF, C. A inclusão das lutas nas aulas de Educação Física escolar. Revista Digital - Buenos Aires -, ano 19, nº 192, mai. 2014. Disponível em: http://www.efdeportes.com/efd192/lutas-nas-aulas-de-educacao-fisicaescolar.htm. Acesso em: 04 jun. 2018.

Recebido em: 14/09/2018

Revisado em: 30/01/2019

Aprovado em: 18/04/2019

Endereço para correspondência:

carlohenriquegolin@hotmail.com

Carlo Henrique Golin

Universidade Federal de Mato Grosso do Sul, DED/CPAN.

Av. Rio Branco, 1270 - Universitário - Caixa Postal 252

Centro

79330070 - Corumbá, MS - Brasil 